\title{
Levels of career commitment and career entrenchment of nurses from public and private hospitals ${ }^{1}$
}

\author{
Mauren Pimentel Lima² \\ Vânia Medianeira Flores Costa $^{3}$ \\ Luis Felipe Dias Lopes ${ }^{3}$ \\ Laércio André Gassen Balsan ${ }^{4}$ \\ Andressa Schaurich dos Santos ${ }^{5}$ \\ Gean Carlos Tomazzoni ${ }^{6}$
}

Objective: to determine the prevalence of the types of relations to career - commitment and entrenchment - of nurses from public and private hospitals. Methods: field survey with a quantitative approach. A total of 237 nurses participated in the survey through a questionnaire with 43 questions about sociodemographic data, occupation, and relation to career. Descriptive statistics, frequency analysis, and Mann-Whitney $U$ test were used for data analysis. Results: nurses from public and private hospitals have a high level of career commitment and a median level of career entrenchment. Conclusions: nurses have a stronger relation of affection and identification to career than a relation of stagnation, maintained primarily due to investments, followed by emotional costs and lack of alternatives. This fact is associated with individuals continuing in nursing and having a strong commitment to activities.

Descriptors: Nursing; Hospitals; Employment.

\footnotetext{
${ }^{1}$ Paper extracted from master's thesis "Commitment and Entrenchment with nurses career: an analysis of taes in public and private hospital institutions", presented to Universidade Federal de Santa Maria, Santa Maria, RS, Brazil.

2 MSc, Professor, Universidade Federal de Santa Maria, Santa Maria, RS, Brazil.

3 PhD, Professor, Universidade Federal de Santa Maria, Santa Maria, RS, Brazil.

${ }^{4}$ Doctoral student, Universidade Federal de Santa Maria, Santa Maria, RS, Brazil. Administrative assistant, Universidade Federal de Santa Maria Santa Maria, RS, Brazil.

${ }^{5}$ Master's student, Universidade Federal de Santa Maria, Santa Maria, RS, Brazil. Scholarship holder from Coordenação de Aperfeiçoamento de Pessoal de Nível Superior (CAPES), Brazil.

${ }^{6}$ Undergraduate student in Administration, Universidade Federal de Santa Maria, Santa Maria, RS, Brazil. Scholarship holder from Fundo de Incentivo a Pesquisa da Universidade Federal de Santa Maria (FIPE-UFSM), Brazil.
}

Corresponding Author:

Vânia Medianeira Flores Costa

Universidade Federal de Santa Maria. Centro de Ciências Sociais e Humanas

Av. Roraima, 1000

Bairro: Camobi

CEP: 97105-900, Santa Maria, RS, Brasil

E-mail: vania.costa@ufsm.br
Copyright () 2015 Revista Latino-Americana de Enfermagem This is an Open Access article distributed under the terms of the Creative Commons Attribution Non-Commercial License (CC BY-NC).

This license lets others distribute, remix, tweak, and build upon your work non-commercially, and although their new works must also acknowledge you and be non-commercial, they don't have to license their derivative works on the same terms. 


\section{Introduction}

Workers committed to the career make it essential for their life ${ }^{(1)}$. On the other hand, factors such as labor market instability and agitation bring effects that can negatively impact on professional career growth and stability, resulting in another form of relation, denominated occupational entrenchment(2).

Commitment and entrenchment to the career are characterized by divergent behavioral attitudes, causing significant personal, organizational, and social impacts $^{(3-4)}$. Committed individuals remain in the career due to emotional feelings that generate strong identification with the profession, feeling motivated in their work because of the feeling of having chosen the right profession; while entrenched individuals remain in the career due to necessity or lack of alternatives.

The formation of relations to the career commitment and entrenchment - arise from the motivation of professionals ${ }^{(5)}$. Therefore, it is important to understand the relation of nurses to hospitals, since they are responsible for the management and coordination of activities directed to patient care. In addition, hospital environments and health institutions are rich in management experiences and practices; however, studies developed by researchers analyzing these approaches are scarce ${ }^{(6)}$

Thus, based on these considerations, we outlined the general objective of the study: to determine the prevalence of the types of relations to career commitment and entrenchment - of nurses from public and private hospitals. And, as specific objectives: i) to determine the level of the nurses' relation to career and how this occurs in each type of hospital (public or private); and ii) to compare the relations to career of nurses from public and private hospitals.

\section{Relation to career: commitment and entrenchment}

Early studies applied to career commitment were dominated by the one-dimensional model(7), also known as occupational, which aims to measure the strong emotional involvement of individuals with their occupation through their identification, positive feelings about the career and desire to continue in the chosen occupation.
Hence, occupational commitment is defined as "one's attitude regarding one's vocation or profession" and, also, an "attitude in relation to an occupation or field"(7).

However, in the mid-1990s, a new career commitment model was created, denominated multidimensional model(8), consisting of a scale composed of three dimensions (identity, insight or career planning, and resilience). In this same line of thought, career commitment is conceptualized as "a motivation to work in a chosen profession"(8).

Career entrenchment is defined as a professional's tendency to continue in the same occupation, due to investments in the career, emotional costs to be lost in the event of a change of occupation, and limited awareness of alternative ways out of the professional field $^{(3,9)}$. The individual is entrenched concerning these conditions and tends to adopt a static, defensive position, as the meaning of the word suggests(5). This immobility, present in the individual's behavior, is triggered both by psychological and economic aspects, making career change difficult to be carried out. Thus, differently from the definition of career commitment, the relation of entrenchment is not formed, exclusively, by psychological dimensions(3), because it seeks to establish a relation that is different from commitment, which, traditionally, is more studied(10).

\section{The nurse from hospitals}

Among the professions in health, nursing is responsible for the management of units, involving provision, supply, maintenance and control of material and human resources for the operation of the service, along with care management, establishing diagnosis, planning, execution and evaluation of care, which includes delegating activities, supervising, and leading the staff(11).

This professional, as a leader of staff and hospitals, is a reference to the others in the group ${ }^{(12)}$. Therefore, hospitals now have a business representation and nursing is influenced by this new hospital context, modifying the nurse's profile, adopting an attitude of critical, reflective, creative and confident leader in relation to decision-making. 


\section{Method}

This is a descriptive field survey with a quantitative approach conducted in the regions of Santa Maria and Santa Cruz do Sul, in the state of Rio Grande do Sul (RS), Brazil. Four hospitals were selected: one public hospital and three private hospitals. Ease of access and authorization from managers of these institutions were decisive in the choice. A total of 156 nurses from public hospitals and 81 nurses from private hospitals participated in the survey, totaling 237 professionals.

The study was approved by the Research Ethics Committee of the Federal University of Santa Maria, under registration number 74045. After approval, data collection was initiated, which was carried out between September and October 2012. As survey instrument, we used a questionnaire with closed questions, consisting of two parts: the first part had eight questions about age, gender, marital status, income, education, children, and type of institution (public or private); the second part comprised the items that assess the individual's relation to career (career commitment, occupational commitment, and career entrenchment).

To measure the variable career commitment, we applied the scale proposed by Carson and Bedeian ${ }^{(8)}$, composed of three dimensions (identity, planning, and resilience) and 12 items. Examples of items: "My type of profession has great personal meaning to me"; "I do not often think about my personal development in this profession"; and "Due to the problems I experience in this profession, I sometimes wonder if it is worthwhile".

To measure occupational commitment, we used the one-dimensional scale proposed by $\operatorname{Blau}^{(7)}$, consisting of seven items. Examples of items: "If I could choose a different profession, that paid the same, I probably would choose it"; "I clearly wish to make my career in my chosen profession"; and "I feel disappointed for having chosen my profession".

Finally, to measure career entrenchment, we applied the scale developed by Carson, Carson and Bedeian(3), structured in three dimensions (career investments, emotional costs, and limitedness of alternatives), consisting of 12 items. Examples of items concerning career entrenchment: "If I left my profession, I would feel without reasonable alternatives"; "Leaving my profession would cause little emotional disturbance to my life"; "Because of my experience and training, there are attractive alternatives available to me in other professions".

Therefore, the second part of the questionnaire totaled 31 items. The questions evaluating the relations were measured by Likert-type scale of five points, ranging from "totally disagree" to "totally agree". We point out that the scales of occupational commitment ${ }^{(4,9-10,13)}$, career commitment, and career entrenchment ${ }^{(2,4,13)}$, used in this study to measure the relation to career, were all validated in Brazil.

Data were analyzed quantitatively with the aid of Microsoft Excel, SPSS - version 18, and SAS - version 9.1. Initially, descriptive (central tendency and dispersion) and exploratory analyses were conducted to investigate accuracy of data entry; distribution of omissions; and sample size and description. Subsequently, we used Cronbach's alpha internal consistency indicator to verify the reliability of the measures of the theoretical constructs used in the questionnaire. Cronbach's alphas obtained in this study for the scales of relation to career were: occupational commitment $\alpha=0.70$; career commitment $\alpha=0.70$; and career entrenchment $\alpha=0.69$. It is noteworthy, therefore, that the Cronbach's alpha coefficient obtained for all variables approached 0.7 , considered a good indicator of reliability by the literature. Importantly, both scales have validation in international and national contexts by researchers from Psychology, Administration, and related fields.

Then, mean and standard deviation were calculated to determine the levels of the relations established by the nurses. To determine the levels of the constructs, we defined three categories: high (mean from $66.67 \%$ to $100 \%$ ), medium (mean from $33.33 \%$ to $66.67 \%$ ), and low (mean from $0 \%$ to $33.33 \%$ ), thus determining the level of relations established by the nurses to their careers. Finally, to determine the differences between the levels of relations of the groups of nurses from public and private hospitals, the Mann-Whitney test was conducted. 


\section{Results}

Regarding the sample profile, most individuals $(65.82 \%)$ work at public institutions. Participants mean age was $30-39$ years (37.13\%), with younger nurses in the age group of $20-29$ years (15.19\%) and the older over 50 years $(19.83 \%)$.

Concerning gender, most professionals were female (89.36\%). Regarding marital status, most participants were married (69.96\%) and had children $(65.11 \%)$, with an average of two children (42.95\%). As for occupational data, most professionals have a specialization degree (70.98\%), career of up to 10 years (38.98\%) and earn between 6 and 10 Brazilian minimum wages (52.63\%).

To identify the nurses' level of relation to career, we standardized the results of the means obtained for each construct in order to classify the level of the relations (commitment and entrenchment) into low, medium, and high (procedure explained in the method section). For this purpose, the overall means and standard deviation obtained for each construct and respective dimensions were analyzed, as shown in Table 1.

Table 1 - General statistics for the constructs and standardized dimensions. Santa Maria and Santa Cruz do Sul, state of Rio Grande do Sul, Brazil, 2012

\begin{tabular}{|c|c|c|}
\hline \multirow{2}{*}{ Theoretical models } & \multicolumn{2}{|c|}{ Statistics } \\
\hline & Standardized mean (\%) & Standard deviation \\
\hline Occupational commitment & 59.33 & 9.49 \\
\hline Career commitment & 72.58 & 9.99 \\
\hline Identity & 80.10 & 16.97 \\
\hline Career planning & 80.41 & 14.60 \\
\hline Resilience & 54.34 & 19.240 \\
\hline Career entrenchment & 44.27 & 8.09 \\
\hline Career investments & 56.60 & 20.05 \\
\hline Emotional costs & 55.47 & 10.99 \\
\hline Limitedness of career alternatives & 53.83 & 17.37 \\
\hline
\end{tabular}

Concerning the first theoretical model, for occupational commitment, the mean value was $59.33 \%$, classified as a medium-level relation. Regarding career commitment, the theoretical model had the highest mean $(\bar{x}=72.58 \%)$, characterizing it as the relation of the highest level. For the dimensions of this relation, the highest means were for planning ( $\bar{x}=80.41 \%$ ), followed by identity $(\bar{x}=80.10 \%)$ and resilience ( $\bar{x}=54.34 \%)$ regarding the career, which, however, had a medium level.

As for career entrenchment, the mean ( $\bar{x}=44.27 \%)$ revealed a medium level for the relation, with dimensions investments ( $\bar{x}=56.60 \%)$, emotional costs ( $\bar{x}=55.47 \%)$ and limitedness of alternatives ( $\bar{x}=53.83 \%)$ having the same behavior. Standard deviations were low, indicating that there was no significant variability among the answers of the participants. This fact reinforces the positive evaluation by the participants regarding the theoretical models used.

As for the determination of the levels of the nurses' relation to the career according to type of hospital, means for each construct by type of institution are shown in Figure 1.

The first construct (career commitment) was the theoretical model with the highest means, for nurses of both public ( $\bar{x}=69.91 \%$ ), and private hospital ( $\bar{x}=77.71 \%)$. The dimensions of this relation had higher means for private hospitals than for public hospitals. For private hospitals, the dimension with the highest mean was identity $(\bar{x}=83.75 \%)$, followed by planning ( $\bar{x}=82.84 \%$ ) and resilience $(\bar{x}=64.19 \%)$. For public hospitals, the means obtained for the dimensions of commitment were also higher for the dimension identity ( $\bar{x}=78.20 \%$ ), followed by planning $(\bar{x}=79.15 \%)$ and resilience $(\bar{x}=49.22 \%)$. 
With regard to occupational commitment, we verified that the mean for the nurses from private hospitals ( $\bar{x}=59.83 \%$ ) was higher than the mean for nurses from public hospitals $(\bar{x}=59.06 \%)$. However, a medium classification was observed for both regarding the level of occupational commitment.

Concerning career entrenchment, mean was slightly higher for private hospitals ( $\bar{x}=45.44 \%)$ compared to public hospitals $(\bar{x}=43.65 \%)$. This construct showed a medium level of relation for both types of hospitals. This behavior of the level of relation remained in its dimensions; however, means were slightly higher for private hospitals, except for the dimension limitedness of alternatives, slightly higher for the public sector.
Thus, to compare the relations to career commitment and entrenchment - of the nurses from public and private hospitals, the Mann-Whitney test was conducted to determine the differences of means. Importantly, values with $\mathrm{p}<0.05$ were considered significant.

Based on the data presented in Table 2, considering the theoretical models surveyed, only career commitment and its dimensions planning and resilience, in addition to the dimension emotional costs from career entrenchment showed statistically significant differences $(p<0.05)$. As for the remaining theoretical models, such differences ( $p>0.05$ ) were not observed, indicating that, regardless of the type of hospital, the difference found for mean possibly occurred due to sampling error.

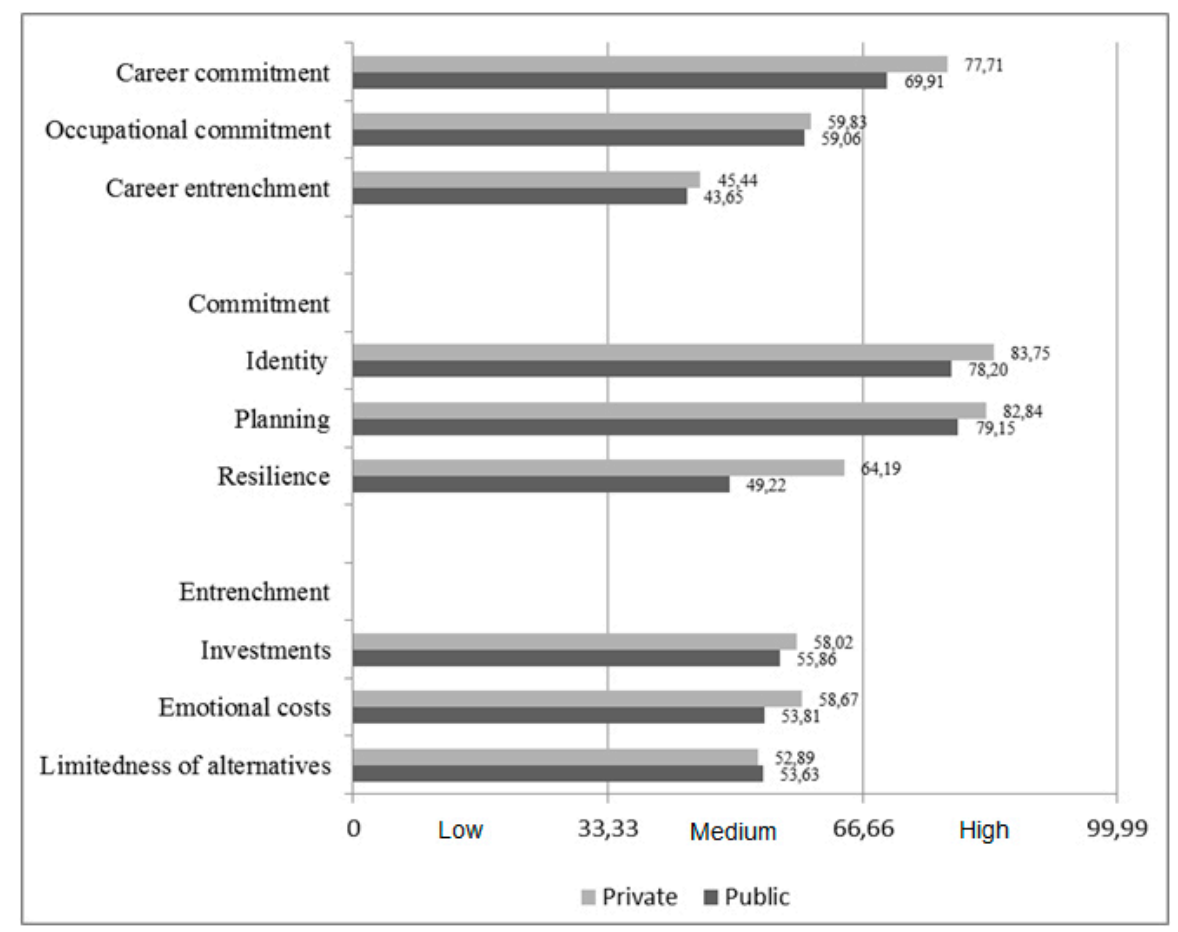

Figure 1 - Standardized mean and classification of the level of the constructs and dimensions by type of hospital

Table 2 - Descriptive statistics of the constructs and respective dimensions for nurses from public and private hospitals. Santa Maria and Santa Cruz do Sul, state of Rio Grande do Sul, Brazil, 2012

\begin{tabular}{|c|c|c|c|c|c|}
\hline \multirow{3}{*}{ Theoretical models } & \multicolumn{4}{|c|}{ Statistics } & \multirow{3}{*}{ p-value } \\
\hline & \multicolumn{2}{|c|}{ Public } & \multicolumn{2}{|c|}{ Private } & \\
\hline & Mean & $\begin{array}{l}\text { Standard } \\
\text { deviation }\end{array}$ & Mean & $\begin{array}{l}\text { Standard } \\
\text { deviation }\end{array}$ & \\
\hline Occupational commitment & 3.02 & 0.45 & 3.07 & 0.42 & 0.6196 \\
\hline Career commitment & 3.40 & 0.36 & 3.71 & 0.38 & $0.0001^{*}$ \\
\hline Identity & 3.55 & 0.46 & 3.59 & 0.49 & 0.2379 \\
\hline
\end{tabular}


Table 2 - (continuation)

\begin{tabular}{|c|c|c|c|c|c|}
\hline \multirow{3}{*}{ Theoretical models } & \multicolumn{4}{|c|}{ Statistics } & \multirow{3}{*}{ p-value } \\
\hline & \multicolumn{2}{|c|}{ Public } & \multicolumn{2}{|c|}{ Private } & \\
\hline & Mean & $\begin{array}{l}\text { Standard } \\
\text { deviation }\end{array}$ & Mean & $\begin{array}{l}\text { Standard } \\
\text { deviation }\end{array}$ & \\
\hline Career planning & 4.03 & 0.63 & 4.22 & 0.69 & $0.0092^{*}$ \\
\hline Resilience & 2.60 & 0.87 & 3.34 & 0.96 & $0.0001^{*}$ \\
\hline Career entrenchment & 2.81 & 0.50 & 2.92 & 0.51 & 0.2535 \\
\hline Career investments & 2.94 & 0.94 & 3.02 & 0.96 & 0.5570 \\
\hline Emotional costs & 2.85 & 0.31 & 3.08 & 0.30 & $0.0001^{*}$ \\
\hline Limitedness of alternatives & 2.80 & 0.82 & 2.76 & 0.39 & 0.6294 \\
\hline
\end{tabular}

$* p<0.05$

\section{Discussion}

In this study, career commitment and career entrenchment were median, differently from other studies $^{(4,10,13)}$, whose mean values for occupational commitment showed a high level of relation.

Results for career commitment level and mean and identity dimension were high, corroborating the values found in another study ${ }^{(13)}$. Considering the means found for the dimensions that are part of the construct career commitment, it is emphasized that the high level of career commitment among nurses does not necessarily imply high levels of resilience. A similar result was found in a survey applied to professors of higher education institutions ${ }^{(4,10)}$. The study found that, when the mean of the dimension resilience is not a significant value, it is assumed that the high level of commitment is not related to the ability to be resilient, i.e., to face adversities found in the profession in order to continue in it ${ }^{(4,10)}$, according to the findings obtained in the present study.

As for career entrenchment, a similar survey ${ }^{(13)}$ also obtained median level for the three dimensions that form this relation. However, in this study, the dimension investments was the highest in relation to means, contrary to the author's findings, whose highest mean was obtained for the dimension emotional $\operatorname{costs}^{(13)}$.

In general, it is observed that the findings obtained showed much more significant levels for career commitment compared to career entrenchment, which is similar to other surveys concerning the subject $^{(4,10,13)}$. This fact reinforces that the nurses surveyed have a stronger relation of identification to their career than a relation of stagnation, maintained primarily due to investments, followed by emotional costs and lack of alternatives.

Regarding the nurses' level of relation to career according to type of hospital, in summary, in both types of institutions, public and private, means for the dimensions commitment, identity, and planning were classified as high level and resilience as median level. A similar study assumed that high levels of career identity and planning, since they are subjective aspects of this relation, would best define the commitment of these professionals(13). Thus, the high level of career planning may indicate that the nurses devise strategies, objectives, plans, and goals, aspects considered by the author as responsible for professional development.

Considering the findings about the dimensions that constitute career commitment, we point out that the professionals from the private context have more significant levels for the dimensions career identity and career resilience, while nurses from the public context plan the nursing career more. Thus, it is verified that professionals from private hospitals show to be better at overcoming the adversities of the occupational context, given the instability of the institution's employment contracts. On the other hand, public hospitals have professionals who plan the career more, due to higher possibilities of growth. These findings are corroborated by a survey conducted with professors from higher education institutions ${ }^{(4,10)}$, which observes that the public context has significant differences from the private context, referring to career conditions. Public institutions provide professionals with a stable career and the possibility of continuous training, which does not occur in the private sector ${ }^{(4,10)}$.

As for occupational commitment, the findings show that there is emotional attachment to the occupation, producing good feelings to continue in the career and seek professional growth. In the specific case, it was found that nurses from public hospitals have higher levels of occupational commitment compared to professionals of private hospitals. These results are similar to those of the study that applied the occupational commitment scale $^{(7)}$ to professors of higher education institutions, 
verifying that professors from public institutions had a higher level of commitment to the profession compared to professors from private universities $(4,10)$.

Regarding career entrenchment, information obtained in the results indicates that large investments in the career tend to cause medium levels of career entrenchment to the studied nurses. Therefore, nurses participating in the study tend to remain stagnant mainly because of the investments in the career rather than because of affective losses and emotional impacts that a change can cause. Regarding the dimensions that are part of career entrenchment, the result found in another study was contrary to the result found in this study ${ }^{(13)}$.

Thus, we emphasize that the values obtained in the results indicate that nurses from private hospital are more committed than nurses from public hospitals. These findings are consistent with the view that the public service brings returns to traditional careers, i.e., those characterized by stability and possibilities of retirement due to length of service ${ }^{(14)}$. Thus, apparently, this lower level of career commitment among nurses from public hospitals may have occurred because of the guarantees provided by positions of such nature(14).

As for the dimensions that are part of career commitment, we observed that nurses from private hospitals have more career planning compared to nurses from the public hospitals. This higher level of planning among nurses from private hospitals may result from conditions provided by the type of institution they work for. Regarding career resilience, nurses from private hospitals are more resilient compared to nurses from public hospitals, indicating that these professionals more easily adapt to the adversities in the occupational context.

Another statistical difference identified among the nurses from public and private hospitals was related to emotional costs, a dimension of career entrenchment. It was evident that nurses from private hospitals estimate the emotional costs, affective impacts, and repercussions on social and family life more than professionals from public hospitals. In addition, there is great homogeneity in the group studied as for the standard deviation found for the constructs and dimensions of the theoretical models applied in this study.

\section{Conclusion}

Career commitment was the predominant relation among the nurses of the study. Nurses have a stronger relation of affection and identification to career than a relation of stagnation, maintained due to investments, emotional costs, and lack of alternatives. This relation of commitment is associated with individuals continuing in nursing and having a strong commitment to activities, indicating that nurses continue in the career because of identification with the profession.

As for career entrenchment, the dimension investment is highlighted. This data indicates that, when leaving the career, the nurse takes into account the investment in training, as well as the efforts in the exercise of nursing.

Concerning limitations of the research, we highlight the study field being restricted to four hospitals and the absence of evaluations with co-workers and immediate supervisors, which may have caused overestimation and underestimation biases to the answers of the subjects. In addition, we point out the difficulty of comparing the findings to other studies on the same topic, researches focusing on the study of organizational behavior in health and nursing institutions. Thus, expanded, regional and national samples are suggested for future studies so results can be generalized.

\section{References}

1. Blau G. Testing for a four-dimensional structure of occupational commitment. J Occup Org Psychol. 2003;76(4):469-88.

2. Magalhães MO. Propriedades psicométricas da versão brasileira da Escala de entrincheiramento na carreira. Psico-USF. 2008;13(1):13-9. doi: 10.1590/S141382712008000100003

3. Carson KD, Carson PP, Bedeian AG. Development and construct validation of a career entrenchment measure. J Occup Org Psychol. 1995;68:301-20. doi: 10.1111/ j.2044-8325.1995.tb00589.x

4. Rowe DEO, Bastos AVB, Pinho APM. Múltiplos comprometimentos com o trabalho e suas influências no desempenho: um estudo entre professores do ensino superior no Brasil. Org Soc. 2013;20(66):501-21. doi: 10.1590/S1984-92302013000300008

5. Carson KD, Carson PP, Phillips JS, Roe CW. A career entrenchment model: theoretical development and empirical outcomes. J Career Develop. 1996;22(4):27386. doi: 10.1007/BF02259996

6. Borba GS, Kliemann Neto FJ. Gestão hospitalar: identificação das práticas de aprendizagem existentes em hospitais. Saúde Soc. 2008;7(1):44-60. doi: 10.1590/S0104-12902008000100005. 
7. Blau GJ. The measurement and prediction of career commitment. J Occup Psychol. 1985;58(4):277-88. doi: 10.1111/j.2044-8325.1985.tb00201.x

8. Carson KD, Bedeian AG. Career commitment: Construction of a measure and examination of its psychometric properties. J Vocational Beh. 1994;44(3):237-62. doi: 10.1006/jvbe.1994.1017

9. Scheible ACF, Bastos AVB, Rodrigues ACA. Comprometimento e entrincheiramento na carreira: integrar ou reconstruir os construtos? Uma exploração das relações à luz do desempenho. Rev Admin. 2013;48(3):530-43. doi: 10.5700/rausp1104

10. Rowe DEO, Bastos AVB, Pinho APM. Comprometimento e entrincheiramento na carreira: Um estudo de suas influências no esforço instrucional do docente de ensino superior. Ver Admin Empresas. 2011;15(6):973-92. doi: 10.1590/S1415-65552011000600002

11. Greco RM. Ensinando a administração em enfermagem através da educação em saúde. Rev Bras Enferm. 2004;57(4):504-7. doi: 10.1590/S003471672004000400026

12. Amestoy SC, Backes VMS, Trindade LL. Canever BP. Produção científica sobre liderança no contexto da enfermagem. Rev Esc Enferm USP. 2012;46(1):227-33. doi: 10.1590/S0080-62342012000100030.

13. Andrade RS, Fernandes SRP, Bastos AVB. Bemestar subjetivo e comprometimento com a carreira: examinando suas relações entre professores de ensino superior. Rev Psicol. 2013,4(2):47-60.

14. Chanlat JF. Quais carreiras e para qual sociedade? Rev Admin Empresas. 1995;35(6):67-75. doi: 10.1590/ S0034-75901996000100003 